\title{
Developing a Sustainable City in a Tropical Area to Create a Balance between Vegetation and Water Bodies
}

\author{
Seyedehzahra Mirrahimi, Nik Lukman Nik Ibrahim, and Mastor Surat
}

\begin{abstract}
This paper aims to investigate the effects of using natural resources that incorporates the basis of a sustainable city design in efforts to improve the urban thermal comfort in a hot and humid climate. Currently, one of the most crucial world environmental issues is urbanization in a hot and humid climate. In tropical areas, if the urban landscape is poorly designed, it will cause outdoor thermal discomfort. Natural plants and water bodies in the hot and humid landscape has a direct influence over the temperature of urban cities. Water bodies, for example, are able to lower the atmospheric temperature; whereas plants also can affect the surroundings passively. The effects of wet surfaces are increased if there is a presence of a shadow. Therefore, vegetation and water bodies are used in designing a sustainable city in order to increase the quality of outdoor thermal comfort in a hot and humid climate. This is hoped to provide a better and more comfortable human living environment.
\end{abstract}

Index Terms-Sustainable city, natural resources, tropical area.

\section{INTRODUCTION}

In this current era of global warming and drastic climate change, important steps should be adopted to protect the climatic conditions and the balance of the ecosystem in urban areas, especially for the coming years. Tropical urbanization still persists as the largest and the most imperative man-made environmental issue internationally [1]. The best designs and landscape planning are the ones which are sensitive to the change of climate and responds efficiently to energy conservation and sustainability [2]. Professional and experienced landscape architects are able to provide valuable design feedback to solve environmental problems. Landscape architects are able to understand the relation between the built and natural elements; thus they play a major role in controlling the negative damages of extreme climatic conditions and bad weathering [3].

The first step that should be taken during the planning phase is to determine the bioclimatic components that are present in the environment, such as forest areas or natural water bodies [4]. The changes in climate, air quality, amount of anthropogenic pollutants, and regional and global atmospheric chemistry originate from cities [5]. By assimilating design characteristics of a sustainable landscape through the use of natural vegetation, the urban temperature of a hot and humid tropical area will be able to be altered (Fig.

Manuscript received February 4, 2014; revised April 25, 2014.

The authors are with the Department of Architecture, National University of Malaysia, Malaysia (e-mail: mirrahimi.elmira@gmail.com, n.lukman@gmail.com, mastorsurat@yahoo.com).
1) [6]. Water bodies and vegetation in urban areas are crucial in balancing and beautifying the ecosystem. The results of this paper describe the strategy of using a sustainable landscape design to raise the performance of urban thermal comfort in a hot and humid climate; therefore contributing towards a better quality of life.

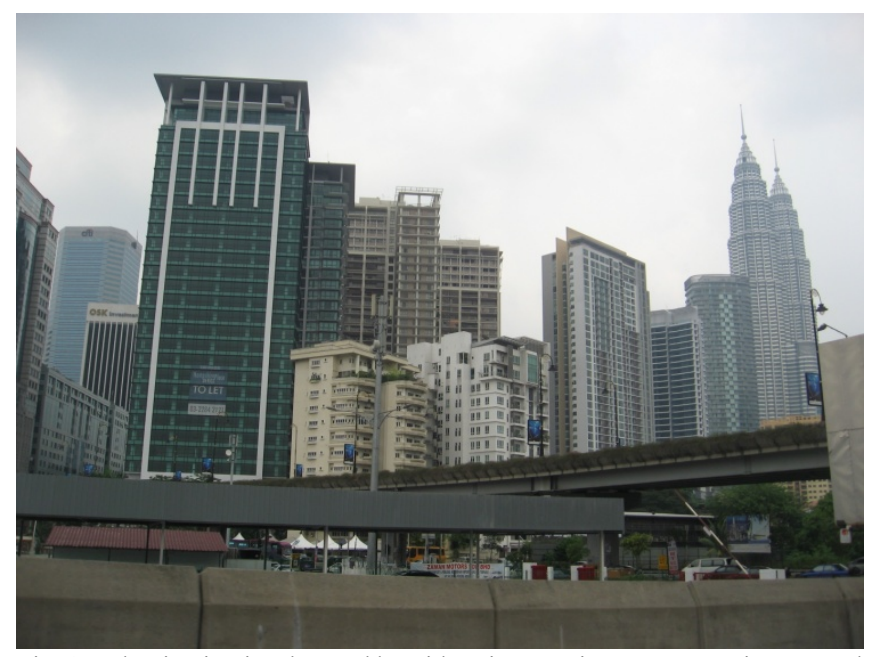

Fig. 1. Urbanization in a hot and humid region requires proper environmental design strategies to ensure sustainability and human comfort (source: Nik Lukman Nik Ibrahim).

During the 1990s, researchers attempt to develop and measure the current condition and value of the world's ecosystem, and the amount and quality of natural resources on Earth [7]. Several factors that have led to landscape degradation are high density of city infrastructures, extreme upsurge of impermeable surfaces, decrease of greenery, and canalization of rivers; these factors ultimately cause the unsustainable development of urban areas [8]. Therefore, it is undeniable that if the designing process of the urban landscape is not given enough attention in hot and humid areas, outdoor thermal discomfort is inevitable. At the present time, the current designs in the urban areas are not positively affected by the local climate and that results in the rise of outdoor thermal discomfort [9]. Due to the increase of the size of cities and the their effect on the environment, there is a need for the urban cities to divert their focus to restoring the balance of the ecosystem by using ecosystem services [7]. The high surface area of natural vegetation in the tropical regions is able to supply shade and evaporative cooling. A number of climatic areas have resorted to using vegetated roofs as a means of improving thermal comfort, reducing air pollution, reducing storm water runoff volume, and increasing runoff water quality [10]-[13]. In the same way, vegetation is able to contribute thermal benefits, eliminate air pollutants, reduce the release of carbon dioxide, and ease 
human stress [14]. However, it is a complicated process to manipulate the ecosystems in urban areas. The environment and ecological systems are drastically altered to accommodate the construction of cities [13], [15]. The responsibility of designing a climate-sensitive city is delegated to the developer, who has to strive to employ environmentally friendly designs with bioclimatic characteristics that are not damaging towards outdoor conditions. 'Bioclimatic' is defined as the relationship between the climate and life, especially how the climate is able to influence living things [6], [14].

\section{Hot AND Humid Climate}

The spatial key can be used to interpret and understand urban climates, observations, and modeling. A city's geographical setting, openness to synoptic events, proximity to water, and surrounding topography have an influence over the city's climate [2]. Until the 1930s, most research on urban climate changes were mainly descriptive; from then till 1965, studies have evolved to become more complex and involves investigating the relationship between climate effects to urban designs [16]. Generally, the surface and air temperature, relative humidity, solar radiation, and wind velocity are climatic factors that are able to alter the outdoor thermal comfort of an area. Therefore, it is deemed necessary for the local authorities and responsible parties to comprehend the relationship between these factors and the climate to determine the right methods and approaches to take to maintain the urban thermal environment. Previous studies in temperate countries have proven that by using the appropriate designs in urbanization, the climate changes were positive [3].

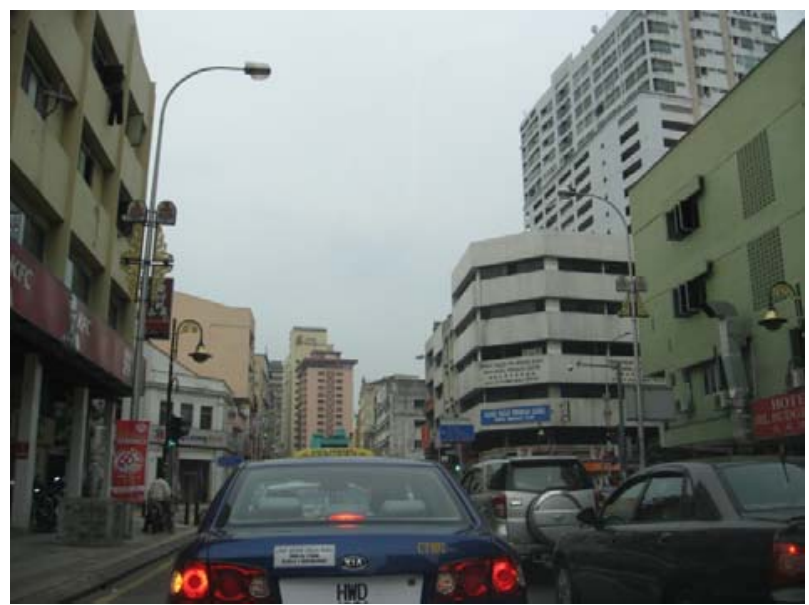

Fig. 2. A hard cityscape devoid of trees in the heart of Kuala Lumpur can easily contribute towards urban heat island (source: Nik Lukman Nik Ibrahim).

However, for hot and humid regions with various climatic changes and urban building designs, the daytime urban heat island (UHI) will aggravate the outdoor thermal discomfort. Few studies that were carried out in tropical regions have proven that in general, daytime UHI are more pronounced than nocturnal UHI (Fig. 2) [17], [18]. Longer hours of sunshine in hot and humid tropical regions result in a higher intensity of solar radiation. This characteristic poses as a challenge for designers to incorporate climate-sensitive elements into urban designs so as to suit the varying climate and yield outdoor thermal comfort [6]. In comparison to temperate and subpolar regions, tropical regions are exposed to the negative effects of urban warmth throughout the year [19]. Characteristics of hot and humid tropical areas are uniform and constant temperature, high humidity, and low wind velocity; therefore, ventilation is critical in the tropics. Thermal comfort can be improved by increasing the flow of wind and area of shade through altering the geometrical design of buildings, such as the height and width, street orientation, and street width [19]-[21]. The high zenith sun angles in the tropics use the construction of canopies and awnings, and growth of vegetation in the geometry and design of buildings. The necessity and advantages of shading are apparent when the general weather patterns, typical dimensions of building blocks, and the activity patterns of people are taken into consideration [19].

\section{NATURAL SOURCES}

The nature in urban regions are usually more consistent and similar in comparison to the natural surroundings in non-urban areas [12]. The function of nature should be assimilated into the design of urban buildings and administration of building constructions to raise the influence of natural elements, such as the flow of wind. During the 2000 s, there was a sudden growth in the allotment of parks and open space according to its ratio to the available natural resources [22]-[24]. There is a certain norm and consistency in the arrangement and construction of buildings, for example, buildings downtown are usually built with greater height; lower residential densities are integrated with parks, green strips along streets, gardens, courtyards, and urban agriculture. In this current age, the services produced by urban ecosystems are directly linked to human activities [15].

Urbanization and overdevelopment have caused the drastic modifications of flora and fauna, and the construction of buildings, roads, and infrastructure. Parks and vegetated open spaces are planted for decorative and aesthetics purposes according to predetermined objectives based on cultural beliefs and practices. Therefore, the design of urban nature is highly dependent on human activities and decisions [15] and the design of urban landscapes require bioclimatic elements. Numerous researchers, such as [21], [25], [26], define the bioclimatic approach as the radical and comprehensive employment of natural vegetation, greenery, water bodies, and landscape design that are suited to climatic variability in urban areas. Vegetation and water bodies are commendable tools to reduce thermal discomfort because they are ecologically friendly, offer a high cooling effect, and encourage a pleasant and healthy living environment through climate adaptation [27]. Urban heat effects can be reduced and alleviated if a higher amount of green spaces are assimilated into developing an urban landscape [1]. Proper procedures and laws should be implemented as part of the decision-making and planning stage of urban development to boost good stewardship and competent use of natural resources [4], [28]. Therefore, nature is a part of the complexity of cities, and each city has its own novel nature 
that humans have a role in creating and maintaining [29], [30]. An expanding and flourishing society demands decent psycho-physical regeneration which can be established through relaying aesthetic and cultural values by placing water bodies and greenery strategically throughout the city [31].

\section{A. Plants and Vegetation}

The atmosphere of the urban landscape needs appropriate planning and designing in order to establish a foundation for thermal improvement [9]. Certain factors that must be considered while planning urban areas with vegetation, such as the choice of plant materials, the arrangement of vegetation, and nativity of the urban space [9]. Hidayat (2010) explained that the endurance and capacity of plants to adapt and survive in its atmosphere is related to the nativity and characteristics of the area. He also clarified the reason vegetation has a higher impact on the cooling effect of 'green' landscapes compared to a heavy urbanized area, especially if there is also a body of water present. The ratio of greenery to the urban area has to be appropriate to offset the effects of thermal discomfort through vegetative cooling [32]. This view was supported by a study sponsored by the Forest Service on the tree canopy cover in urban landscapes [33]-[35], and by other studies on watersheds and many urban ecosystem processes [36]-[39]. As for hot and humid climatic zones, many researchers [14], [29], [40] recognize the importance of solar shading in the design of urban structures because it can be used to keep heat gain at minimum levels and maximize coverage over urban surfaces [1]. As hot and humid tropics mainly require shading and solar filtration, Shahidan et al., $(2010,2011)$ and Hidayat (2010) asserts that it would be more favorable to plant trees that grow to have greater height, wider canopy, larger leaves, and thicker branch coverage to filter radiation [6].

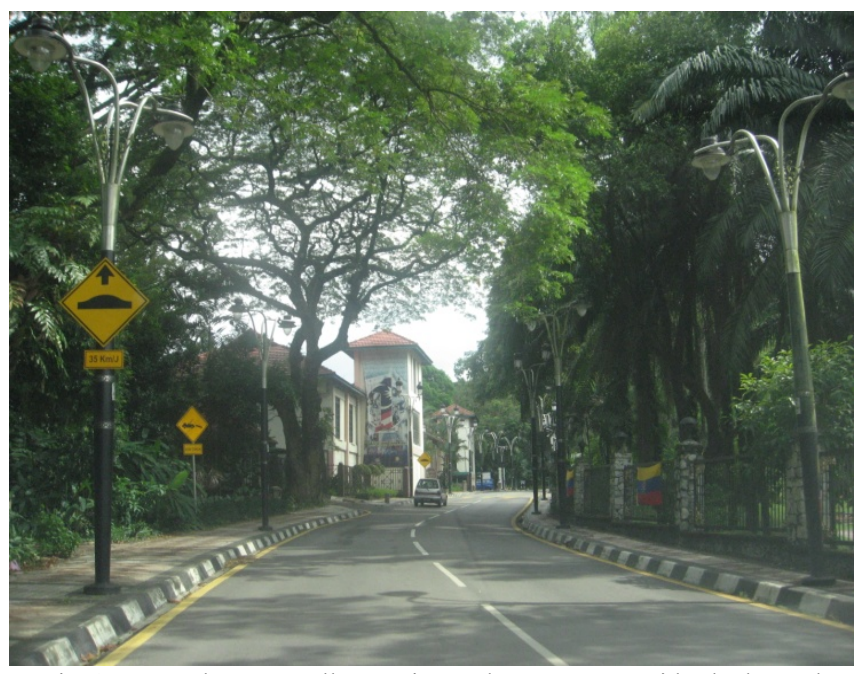

Fig. 3. Trees along a small street in Kuala Lumpur provide shades and cooling effect (source: Nik Lukman Nik Ibrahim).

Trees are the best tools to lower the urban temperature, whether planted individually or in masses, due to their transpiration process and morphological features. Vegetation can control and mitigate the decrease of temperature by providing shade, lowering ground and air temperature, filter solar radiation, provide ventilation, and diminish reflective glare as shown in Fig. 3 [1], [41]. Sham (1990) researched the effects of vegetation in Kuala Lumpur, Malaysia, and concluded that in a hot afternoon, the overall temperature in an urban area could be reduced by $4^{\circ} \mathrm{C}$ to $5^{\circ} \mathrm{C}$ if there is a presence of dense vegetation. In Singapore, the difference of temperature between well-planted areas and the urban core can be up to a maximum of $4.01^{\circ} \mathrm{C}$. Other researchers have noted that urban greening efforts like growing short vegetations also can alter urban temperature through transpiration [6], [35]. Although heat island effects can raise the level of thermal discomfort, the strategic location and landscape of hot and humid tropics offers the potential of shading and transpirational [42].

According to research, tropical trees are able to constrict the percentage of solar radiation, for example, the Messuaferrea (Ironwood Tree) can lower solar radiation by as much as $92.55 \%$; while the Hurracrepitans (Indonesian Umbrella Tree), up to $79 \%$. This reduces the ground surface temperature because the canopy protects the ground from direct sunlight and radiation. Hence, these natural characteristics serve as a means to regulate and control the urban climate, and therefore these benefits can be taken advantage of by landscape designers [1]. More attention and scrutiny has been given to the process of landscape design and the application of natural vegetation as mitigation methods to control the increase of urban thermal discomfort. Due to its ability to improve urban temperature with minimal expenditures [10], natural vegetation can have passive effects onto urban designs (Yeang, 2006). By integrating the scientific knowledge about vegetation and water bodies with the creativity and inventiveness of design, the landscape design approach can balance the ecosystem and counter the effects of urban thermal discomfort. In addition, the reduction of urban temperature by using landscape design can be enforced from the regional to the local or micro scale [3]; thus, making it the most comprehensive mitigating approach to reduce heat island effects [6].

\section{B. Water Bodies}

Other than the use of vegetation, water bodies can also be manipulated and designed according to the climatic needs of a particular region [6]. Water bodies are natural ecological structures which are made up of a volume of water and forms a physiographical feature [19], [20]. Urban water bodies, situated among parks and residential areas, play a crucial role in the ecological system in urban cities [43]. The rate of evaporation on the surface of water bodies are affected by the geometrical characteristics, region, and the surrounding landscapes [44]. It is concluded that the water bodies' geometry, shape, and depth can influence the variations of the Urban Cool Island (UCI) intensity; however, it is negatively correlated to the UCI efficiency of water body area [35], [44]. This means that even if the total area of water bodies is divided into several small water bodies, the benefits and positive effects will still remain the same. Besides that, the cooling potential of the water bodies is not dependent on the shape and depth of the volume of water [35]. Therefore, the effectiveness of cooling relies on the measurements of the water bodies and the threshold with landscape environments. These concerns are taken into consideration when designing 
a water feature in urban designs [6]. The role of urban water bodies are more apparent during hot summer days since it can contribute to human comfort by lowering the temperature of the surroundings and increase the humidity [43]. The presence of a shadow surface would also further magnify the cooling effects of water bodies. This proved the results of [44] which stated that there is a significant relationship between the location and exchange of thermal loads from water bodies and the surrounding landscape. Basically, the best method to provide cooling effects in high temperature locations is to have many 'wet surfaces' to maximize the evaporation rate [35]. If water bodies can be strategically placed to take advantage of air movement patterns at a local scale and more trees are planted around water bodies, the potential of cooling the environment is highly beneficial (Fig. 4) [21]. A study by Sun and Chen (2012) indicated that the mean temperature of water bodies was $29.49^{\circ} \mathrm{C}$, which is lower than the green land $\left(30.07^{\circ} \mathrm{C}\right)$ and built-up area $\left(32.86^{\circ} \mathrm{C}\right)$. Urban water bodies can beautify the surroundings, maintain ecological systems, and improve human interactions in the urban city. However, most studies do not focus on their effect on human comfort [43].

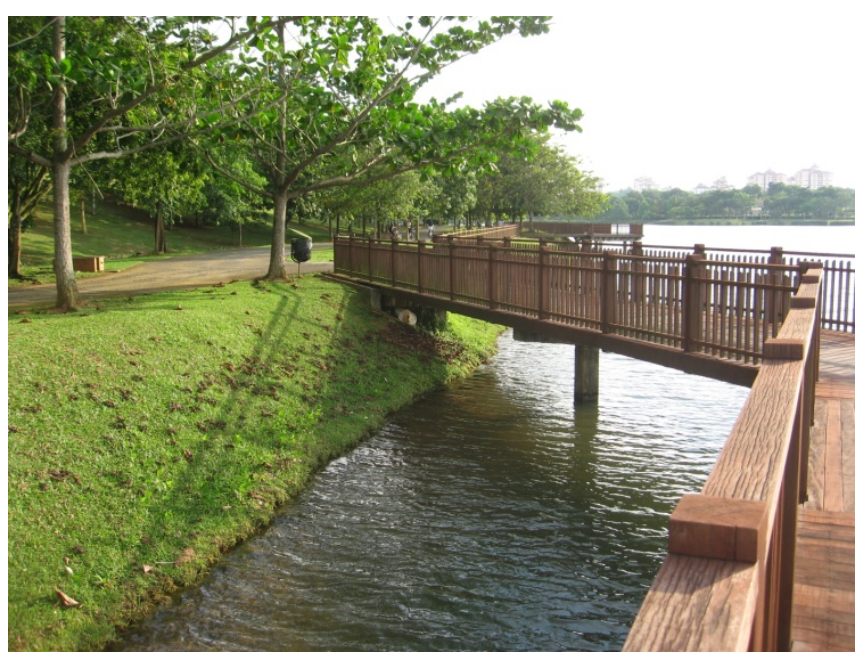

Fig. 4. A breezy cooling lake surrounded with trees in Putrajaya botany park (source: Nik Lukman NIK Ibrahim).

\section{HUMAN COMFORT}

Human comfort is a biometeorologyical parameter to assess the level and standard of comfort at various climate conditions. The concept of heat exchange between the human body and near-ground atmosphere is used to measure human comfort [43]. Cities are human creations which have a strong effect on ecological and geochemical modifications [45]. However, from a development and design point of view, the findings of previous studies are not directly applicable unless the human consequences of urban climate change are specified. Thus recently, climate-sensitive designers and landscape architects are paying more attention to the necessity of human comfort [8]. A sustainable city gives precedence to high quality of life and human health which can be achieved by maintaining a certain standard of environmental performance and ecosystem services [7]. According to several past studies, meteorological factors, especially temperature, have an influence over the human physiological condition. This is because most of the human bodily functions are dependent on the changes of the body temperature. Humidity is another factor that can cause the heat balance and body sensations to change when the temperature of the body is higher than $35.1^{\circ} \mathrm{C}$, this is due to the sudden evaporation of sweat which alters the normal conditions of the human body [44]. Spatial organization is therefore very important when dealing with intense urban development because their effects can affect a city and its people in the long run, whether aesthetically, culturally, ecologically, or in terms of their standard of living and quality of health [7].

\section{CONCLUSION}

In conclusion, vegetation should be selected due to their ecologically friendly nature and restorative properties instead of only for their aesthetic value, and the species of a plant should be selected according to the bioclimatic needs of a city. In addition, native vegetations assimilate easily into the local environment and require less attention and maintenance effort. However having said that, developers can still incorporate plants with beautification purposes but only if those plants can also actively contribute towards reducing urban temperature. City authorities usually do not plant trees and vegetation near urban water bodies due to human activity requirements, causing a reduction of the sun blocking effect. A greater height and density of trees can prevent direct solar radiation and create areas with better shade. Therefore, the effects of shading, regulating temperature and humidity are more prominent as the distance between trees and water bodies becomes closer.

\section{ACKNOWLEDGMENT}

This article on sustainability is partially funded by the National University of Malaysia's research grant, UKM-KK-02- FRGS0203-2010.

\section{REFERENCES}

[1] S. K. S. O. Thani, N. H. N. Mohamad, and S. Idilfitri, "Modification of urban temperature in hot-humid climate through landscape design approach," A Review. Procedia-Social and Behavioral Sciences, vol. 68, pp. 439-450, 2012.

[2] N. Daouas, "A study on optimum insulation thickness in walls and energy savings in Tunisian buildings based on analytical calculation of cooling and heating transmission loads," Applied Energy, vol. 88, no. 1, pp. 156-164, 2011.

[3] R. Hyde, Bioclimatic Housing: Innovative Designs for Warm Climates, Earthscan, 2008.

[4] S. Sani, Pembandaran Dan Iklim: Implikasinya Terhadap Perancangan Bandar Di Rantau Tropika Rendah, Penerbit Universiti Kebangsaan Malaysia, 1989.

[5] A. H. F. Ashrae, American Society of Heating, Refrigerating and Air-Conditioning Engineers, Inc. Atlanta, 1997.

[6] A. Standard, Thermal Environmental Conditions for Human Occupancy, American Society of Heating, Refrigerating and Air conditioning Engineers, p. 145, 2004.

[7] S. Pincetl, Nature, Urban Development and Sustainability-What New Elements are Needed for A More Comprehensive Understanding? Cities, 2012.

[8] I. Wagner and M. Zalewski, "Ecohydrology as a basis for the sustainable city strategic planning: focus on Lodz, Poland," Reviews in Environmental Science and Biotechnology, vol. 8, no. 3, pp. 209-217. 2009. 
[9] M. S. A. Homoud, "Performance characteristics and practical applications of common building thermal insulation materials," Building and Environment, vol. 40, no. 3, pp. 353-366. 2005.

[10] S. Onmura, M. Matsumoto, and S. Hokoi, "Study on evaporative cooling effect of roof lawn gardens," Energy and Buildings, vol. 33, no. 7, pp. 653-666, 2001.

[11] M. Köhler et al., "Green roofs in temperate climates and in the hot-humid tropics-far beyond the aesthetics," Environmental Management and Health, vol. 13, no. 4, pp. 382-391, 2002.

[12] T. Carter and C. R. Jackson, "Vegetated roofs for stormwater management at multiple spatial scales," Landscape and Urban Planning, vol. 80, no. 1, pp. 84-94, 2007.

[13] N. H. Wong et al., "Life cycle cost analysis of rooftop gardens in Singapore," Building and Environment, vol. 38, no. 3, pp. 499-509, 2003.

[14] C. Grimmond et al., "Climate and more sustainable cities: Climate information for improved planning and management of cities (producers/capabilities perspective)," Procedia Environmental Sciences, pp. 247-274, 2010.

[15] J. Xu et al., "Evaluation of human thermal comfort near urban waterbody during summer," Building and environment, vol. 45, no. 4, pp. 1072-1080, 2010

[16] F. Baer, N. L. Canfield, and J. M. Mitchell, "Climate in human perspective: a tribute to Helmut E. Landsberg," Kluwer Academic Pub. vol. $15,1991$.

[17] H. Taha, "Urban climates and heat islands: albedo, evapotranspiration, and anthropogenic heat," Energy and Buildings, vol. 25, no. 2, pp. 99-103, 1997.

[18] S. K. Jusuf et al., "The influence of land use on the urban heat island in Singapore," Habitat International, vol. 31, no. 2, pp. 232-242, 2007.

[19] M. Ahmad, D. R. Ossen, and J. Kui Lam, Effect of Urban Geometry on Solar Insolation Threat in JSNAC (Pilot Study), 2008.

[20] R. Emmanuel, "A hypothetical 'shadow umbrella'for thermal comfort enhancement in the equatorial urban outdoors," Architectural Science Review, vol. 36, no. 4, pp. 173-184, 1993.

[21] R. Emmanuel, An Urban Approach to Climate Sensitive Design: Strategies for the Tropics, Taylor \& Francis, 2005.

[22] C. G. Boone et al., "Parks and people: an environmental justice inquiry in baltimore," Maryland. Annals of the Association of American Geographers, vol. 99, no. 4, pp. 767-787, 2009.

[23] N. Heynen, H. A. Perkins, and P. Roy, "The political ecology of uneven urban green space the impact of political economy on race and ethnicity in producing environmental inequality in Milwaukee," Urban Affairs Review, vol. 42, no. 1, pp. 3-25, 2006.

[24] J. Wolch, J. P. Wilson, and J. Fehrenbach, "Parks and park funding in Los Angeles: An equity-mapping analysis," Urban geography, vol. 26, no. 1, pp. $4-35,2005$.

[25] N. Fintikakis et al., "Bioclimatic design of open public spaces in the historic centre of Tirana, Albania," Sustainable Cities and Society, vol. 1, no. 1, pp. 54-62, 2011.

[26] O. Corbella and M. Magalhaes, "Conceptual differences between the bioclimatic urbanism for Europe and for the tropical humid climate," Renewable Energy, vol. 33, no. 5, pp. 1019-1023, 2008.

[27] R. Sun and L. Chen, "How can urban water bodies be designed for climate adaptation?" Landscape and Urban Planning, vol. 105, no. 1, pp. 27-33, 2012.

[28] I. Eliasson, "The use of climate knowledge in urban planning," Landscape and Urban Planning, vol. 48, no. 1, pp. 31-44, 2000.

[29] R. Emmanuel, "Thermal comfort implications of urbanization in a warm-humid city: the Colombo Metropolitan Region (CMR), Sri Lanka," Building and Environment, vol. 40, no. 12, pp. 1591-1601, 2005.

[30] C. Kennedy, S. Pincetl, and P. Bunje, "The study of urban metabolism and its applications to urban planning and design," Environmental Pollution, vol. 159, no. 8, pp. 1965-1973, 2011.

[31] M. A. Aktacir, O. Büyükalaca, and T. Yılmaz, "A case study for influence of building thermal insulation on cooling load and air-conditioning system in the hot and humid regions," Applied Energy, vol. 87, no. 2, pp. 599-607, 2010.

[32] M. Ashourian et al., "Optimal green energy management for island resorts in Malaysia," Renewable Energy, vol. 51, pp. 36-45, 2013.
[33] G. McPherson et al., "Municipal forest benefits and costs in five US cities," Journal of Forestry, vol. 103, no. 8, pp. 411-416, 2005.

[34] D. J. Nowak and J. F. Dwyer, "Understanding the benefits and costs of urban forest ecosystems, in Urban and community forestry in the northeast," Springer, pp. 25-46, 2007.

[35] T. L. Tiang and D. Ishak, "Technical review of wind energy potential as small-scale power generation sources in Penang Island Malaysia," Renewable and Sustainable Energy Reviews, vol. 16, no. 5, pp. 3034-3042, 2012.

[36] E. Andersson, Urban Landscapes and Sustainable Cities, 2006.

[37] M. Cadenasso et al., "Exchanges across land-water-scape boundaries in urban systems," Annals of the New York Academy of Sciences, vol. 1134, pp. 213-232, 2008

[38] P. M. Groffman et al., "Soil nitrogen cycle processes in urban riparian zones," Environmental science \& technology, vol. 36, no. 21, pp. 4547-4552, 2002.

[39] S. T. Pickett et al., "Social-ecological science in the humane metropolis," Urban Ecosystems, vol. 14, no. 3, pp. 319-339, 2011.

[40] B. Givoni, Climate Considerations in Building and Urban Design, Wiley, 1998

[41] J. Wardoyo et al., "Vegetation configuration as microclimate control strategy in hot humid tropic urban open space," in Proc. International Seminar in Sustainable Environment \& Architecture $+2^{\circ}$ International Symposium \& Exhibition in Sustainable Energy \& Environment, 2008.

[42] T. Mahlia, B. Taufiq, and H. Masjuki, "Correlation between thermal conductivity and the thickness of selected insulation materials for building wall," Energy and Buildings, vol. 39, no. 2, pp. 182-187, 2007.

[43] R. Costanza et al., "The value of the world's ecosystem services and natural capital," Nature, vol. 387, no. 6630, pp. 253-260, 1997.

[44] H. Ong, T. Mahlia, and H. Masjuki, "A review on energy scenario and sustainable energy in Malaysia," Renewable and Sustainable Energy Reviews, vol. 15, no. 1, pp. 639-647, 2011.

[45] P. M. Vitousek et al., "Human domination of Earth's ecosystems," Science, vol. 277, no. 5325, pp. 494-499, 1997.

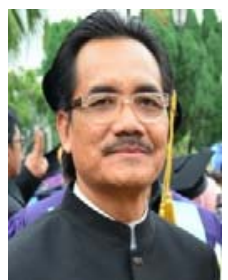

Mastor Surat graduated with a diploma of architecture in 1985 and a bachelor of architecture in 1988 from Universiti Teknologi Malaysia (UTM). In 2008, he obtained his master of letters from The National University of Malaysia (UKM) for his research thesis on typology development of traditional Malay mosque of the Malay world. He Obtained his $\mathrm{Ph} . \mathrm{D}$ degree in architecture from UKM in 2012 for his research thesis on the issue of dome as main element of mosque architecture in Malaysia.

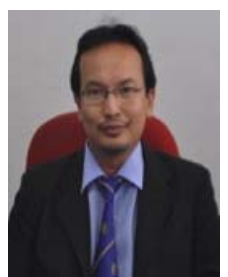

Nik Lukman Nik Ibrahim was born in Kota Bharu, Kelantan, Malaysia. He graduated with bachelor of environmental design, 1997. He received his bachelor of architecture in 1999 from the University of Tasmania, Hobart and Launceston. He obtained master of philosophy in architecture in 2002 and doctor of philosophy in 2009 from the University of Sydney, New South Wales, Australia. He Work briefly with the University of Malaya and an architectural practice, FAU Akitek in Kuala Lumpur before becoming a lecturer at the National University of Malaysia (UKM). Currently he is a senior lecturer and the head of the Architecture Department, UKM.

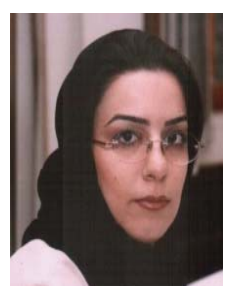

Seyedehzahra Mirrahimi with a bachelor of architecture from Azad University of Iran (Qazvin). In 2003, She obtained her master of architecture from Azad University of Iran (Qazvin) for her research thesis "story land for children. She studies doctor of philosophy (Ph.D) in architecture at National University of Malaysia for her research thesis on rule of thumb daylighting for lecture room in Malaysia. 